\title{
Surveillance of Hospital Acquired Infection from Frequently Handled Surfaces in a Tertiary Care Teaching Hospital
}

\author{
E. Subbalakshmi* \\ Department of Microbiology, Sambhram Institute of Medical Sciences and Research, \\ $K G F$, India \\ *Corresponding author
}

\section{A B S T R A C T}

\section{Keywords}

Disinfectants,

Cleaning,

Surveillance

\section{Article Info}

Accepted:

10 January 2018

Available Online:

10 February 2018
Hospitals and other health care institutions are engaged in essential and intensive efforts to prevent health care associated infections (HAI). HAIs are of particular concern to infection prevention professionals because many of these are caused by rapidly developing strains of multidrug resistant organisms. The preventive aspect of hospital acquired infection (HAI) surveillance is difficult to assess. Experts agree that careful cleaning and disinfection of environmental surfaces are essential elements of effective infection prevention programs. Many different hospital staff is involved in monitoring the minimum levels of hospital infection and should be aware of their role in surveillance. Our aim was to investigate the effect of HAI surveillance on frequently handled surfaces from high risk areas and from wards in a tertiary care new teaching hospital. A prospective study was done for a period of 3 months from Jan-Apr 2017. Active surveillance was done on frequently handled surfaces like front desk, door handle, telephone, monitor, cot railings and patients' bedside tables. About 6 swabs were taken from each of these surfaces in various wards and intensive care units (High risk areas) every week. (i.e. 60 swabs per week). Active surveillance of the study showed Staphylococcus aureus and Klebsiella pneumoniae and aerobic spore bearers in places like front desk, telephone, and injection trolleys which are frequently handled by HCWs and the patients. There is no easy way to keep a hospital clean, though we may claim that it is $100 \%$ clean. There is need for a more integrated approach to infection and occupational acquired illness prevention. Removing invisible dirt from today's hospitals and the future ones requires sufficiently trained staff, continuous surveillance of environmental hygiene and bioburden education, constant upgrading of practice and two-way communication between those responsible for cleaning and those responsible for infection control. Staphylococcus aureus and Klebsiella pneumoniae, the common causative agents of hospital acquired infections, present in frequently handled surfaces can be prevented by effective disinfection. Environmental service departments should consider the use of newer disinfectants and no-touch decontamination technologies to improve disinfection of surfaces in health care centres. Regular surface cleaning with $1 \%$ hypochlorite helped in prevention of infection in our hospital which was proved in our study, since there was no growth found if surface cleaning was done twice every day in high risk areas, and daily in wards. 


\section{Introduction}

The field of hospital infection control started in the middle of the 1800s when Semmelweis and Nightingale introduced sanitation and hygienic practices into hospitals. However, modern infection control as practiced today, was initiated when a series of widely publicized hospital outbreaks of Staphylococcus aureus infection in the 1950s occurred in North America and the UK. In response to these outbreaks, various health care institutions, including the American Hospital Association (AHA), initiated programs for the surveillance and control of these infections (Ling et al., 2011). The 1980s represented a landmark in the evolution of concepts of hand hygiene in health care. Normalhuman skin is colonised with bacteria. Total bacterial counts on the hands of medical personnel have ranged from $3 \times 10^{4}$ into $4 \times 10^{6}$. Transient flora, which colonize the superficial layers of the skin are more amenable to removal by routine hand washing. Transient flora are the organisms most frequently associated with health care associated infections.

Preventing infections requires sustained compliance with a number of good practice areas- including the provision of clean environment, aseptic techniques, and the management of invasive devices. However, evidence shows that improving hand hygiene contributes significantly to the reduction of HCAIs. Evidence suggests that many health care professionals, including nursing staff, do not perform hand hygiene as often as is required or use the correct technique There are several studies showing cross contamination of organisms by hands (Ducel et al., 2002]. Factors that influence the transfer of microorganisms from surface to surface and affect cross contamination rates are type of organism, source and destination surfaces, moisture level and size of inoculum. For the past 30 years, nosocomial infection has been defined as 'An infection acquired in hospital by a patient who was admitted for a reason other than that of infection. Many factors promote infection among hospitalised patients: decreased immunity among patients, the increasing variety of medical procedures and invasive techniques creating potential routes of infection and transmission of drug resistant bacteria among crowded hospital population where poor infection control practises may facilitate transmission (Quinn et al., 2015). Non critical environmental surfaces can serve as reservoirs of microbial contamination. Surfaces frequently touched by hands (e.g.) bedside table, bedrails pose a notable challenge in this regard. Transfer of microbial contamination by hand contact with environment surfaces or equipment surfaces to patients, other workers or other surface represents an indirect mode of transmission. Surveillance is generally recognized as essential to the practice of hospital infection control. Surveillance has been defined as ongoing systematic collection, analysis, interpretation of health data essential to the planning, implementation, evaluation of infection control practices closely integrated with timely dissemination of these data to those who need to know.

Active surveillance has been used successfully to control infections in hospitals. Passive surveillance involving the reporting of infections by the physicians is considered to be complementary (Moore and Griffith, 2007). Surveillance must be performed in a systemic way with the aim of reducing rates of hospital infection. Monitoring the data on a regular basis will help infection control personnel to identify HAI outbreaks early and help them to control it promptly. A good surveillance programme with good compilation of data provides supporting evidence of quality health management in the hospital (Nadova et al., 2016). 


\section{Aim and objectives}

The aim and objective of this study is to find out the importance of environmental hygiene and hand hygiene in prevention of hospital infection control, by carrying out active surveillance on frequently handled surfaces in a new tertiary care teaching hospital and thereby setting a protocol for prevention of infection.

\section{Materials and Methods}

A prospective study was conducted for a period of 3 months from Jan-April 2017. Active surveillance study was done on frequently handled surfaces from various wards, ICUs and OPDs from front desks, injection trolleys, cot railings, patient bed side table and telephone. About 6 swabs per ICU/ward were taken at weekly intervals for a period of 3 months from Jan-Apr 2017. Swabs were streaked on Nutrient agar and Blood agar plates and incubated aerobically at 37 degrees for 16-18 hrs. Identification of the organisms was done based on gram stain and from the biochemical reactions. We used Clinical and Laboratory Standard Institute (CLSI 2017) (Clinical and Laboratory Standards Institute, 2017). as a guide line for the identification of organisms and antibiotic susceptibility.

\section{Results and Discussion}

Out of 60 swabs taken from various wards and ICUs per week we found growth mainly in those taken from the ICUs. The organisms were present in surfaces like telephone, Injection trolleys and front desk which are in constant touch with the patients and HCWs. The total number of swabs tested over a period of 3 months was 720 . We isolated mainly $S$. aureus (MRSA) and Klebsiella pneumoniae after confirmation with the biochemical reactions. In case of $S$. aureus we found most of them to be resistant to cefoxitin but sensitive to vancomycin (MRSA) which was community acquired (Table 1). Contamination of hospital equipment, medicine and water supplies with hospital pathogens is a wellrecognised cause of outbreaks of infection. Patients are the prime sources of contamination, so surfaces in the vicinity of patients that are touched frequently by HCWs and patients, termed high touch surfaces have a higher frequency of contamination than other sites, because nearly $10^{6}$ skin squames containing viable microorganism are shed daily from normal skin (Ling et al., 2011). Hence it is not surprising that patient gowns, bedlinen, bedside furniture and other objects in the immediate environment of the patient become contaminated with patient flora. Contamination of the inanimate environment has also been detected on ward, hand wash station surfaces, and most of the organisms isolated were Staphylococci (Moore and Griffith, 2007). We stressed the importance of hand hygiene. Hand hygiene can be undertaken using soap and water or hand sanitisers, i.e., alcohol hand gels. Although it is not possible to completely sterilise hands, the number of bacteria present can be reduced significantly through good hand hygiene practice (Ling et al., 2011). Hands should be washed whenever they are suspected of being soiled and before the care of a new patient. The presence of a pathogen on a surface does not necessarily present a transmission risk. The infectious doses for most environmental pathogens associated with healthcare appear to be low. The presence of pathogens on a surface at any concentration may be a risk for transmission and this is reflected in proposed guidelines for microbiological hygiene standards (Ling, 2008). We used $1 \%$ hypochlorite which is a low surface disinfectant for surface disinfection and we found no growth if used daily, especially in ICUs. Frequently touched surfaces in patient care areas should be cleaned using a detergent solution, and more frequently than surfaces 
with minimal hand contact. After cleaning with the disinfectant, swabs taken from the same places showed no growth. Since hypochlorite is a sporicidal, bactericidal and virucidal, we found this to be an effective disinfectant. Minimize the contamination levels of the disinfectant solution and equipment used for cleaning by ensuring proper dilution of the disinfectant, frequently changing the disinfectant solution and by not dipping a soiled cloth into the disinfectant solution.

Over the past 30 years, nosocomial infection surveillance, prevention and control programmes have been integrated into hospitals and other health care institutions to ensure the well-being of patients, staff, visitors and others in the health care environment. In 1970, the centre for disease control and prevention recommended that hospitals establish positions for an infection control nurse and a hospital epidemiologist. The most important data management activity of infection control programmes is the surveillance of nosocomial infection and other adverse events. The collection, analysis and dissemination of surveillance data has been shown to be the single most important factor in the prevention of nosocomial infection. In our study we conducted surveillance on frequently handled surfaces in wards and various ICUs. Nosocomial infections have been recognised for more than a century as a critical problem affecting the quality of health care provided in hospitals. A significant proportion of infections result from cross contamination and transmission of microorganisms via the hands of health care workers (Marfan, 2013). The CDC (centre for disease control) has documented that HAIs are caused by many pathogenic organisms present on floors, bedding, mops and furniture in the hospital environment, also called high touch points/object by the CDC. Through clinicians' hands and the environment, patients may be exposed to pathogenic bacteria such as MRSA and enterococcus and multi drug resistant Klebsiella pneumoniae. Removing pathogens from handles, switches, buttons, knobs and other frequently touched sites is more likely to have an impact on patient transmission than cleaning inaccessible surfaces such as high shelves, ledges or ceilings or low touch surfaces such as walls and window panes. Failure of housekeepers to use adequate number of wipes per room can result in poor cleaning of surfaces. Use of wipes without sufficient antimicrobial activity against target pathogens can result in poor disinfection of surfaces and can lead to spread of pathogens from one surface to another (William et al., 1998). Microfiber clothes or mops or ultramicrofiber clothes are among the relatively newer methods for applying liquid disinfectants to the surfaces. Water serves as a medium for spreading microbes around the environment.

Both detergent and disinfectant wipes and clothes can be used to wipe over non critical areas on a routine basis obviating the need for decontamination. Failure to adequately disinfect patients' room at the time of discharge contributes to the increased risk of resistant pathogens among patients admitted to a room where the prior room occupant was colonised or infected with the multidrug resistant pathogens (Australian guidelines for the prevention and control of infection in health care, 2010). The incidence of hospital acquired, methicillin resistant staphylococcus aureus continue to rise globally. Attempts to control this spread have relied on three measures: hand hygiene among health care workers, restriction of antibiotics and the detection and isolation of infected or colonised patients. Prevention of bacterial contamination by transient flora and possible subsequent infection requires timely hand cleansing that may be achieved by washing or disinfecting the hands (Ramphal et al., 2014). 
Table.1 Isolation of organisms from wards

\begin{tabular}{|c|c|c|c|c|}
\hline $\begin{array}{l}\text { Places of } \\
\text { collection }\end{array}$ & Surgical wards & Medical wards & $\begin{array}{l}\text { Orthopaedic } \\
\text { wards }\end{array}$ & $\begin{array}{l}\text { Paediatric } \\
\text { wards }\end{array}$ \\
\hline Front desk & S.aureus & $\begin{array}{l}\text { Klebsiella } \\
\text { pneumoniae }\end{array}$ & S.aureus & S.aur eus \\
\hline $\begin{array}{l}\text { Dressing } \\
\text { trolley1 }\end{array}$ & S.aurcus & S.aur cus & K.pn cumoniac & NG \\
\hline $\begin{array}{l}\text { Patient cot } \\
\text { railings }\end{array}$ & NG & S.aur eus & NG & NG \\
\hline Phone & S.anrens & S.aureus & NG & NG \\
\hline $\begin{array}{l}\text { Patient side } \\
\text { lable }\end{array}$ & NG & NG & NG & NG \\
\hline
\end{tabular}

Table.2 Effect of disinfectant (1\% hypochlorite) (ICUs and wards)

\begin{tabular}{|c|c|c|c|c|}
\hline $\begin{array}{l}\text { Places of } \\
\text { collection } \\
\text { Front desk }\end{array}$ & $\begin{array}{l}\text { MICU } \\
\text { NG }\end{array}$ & $\begin{array}{l}\text { SICU } \\
\text { NG }\end{array}$ & $\begin{array}{l}\text { MED Iriage } \\
\text { NG }\end{array}$ & $\begin{array}{l}\text { Dial y̧sis u uil } \\
\text { NG }\end{array}$ \\
\hline Monitor & NG & & NG & NG \\
\hline $\begin{array}{l}\text { Dressing } \\
\text { trolley }\end{array}$ & NG & NG & YG & NG \\
\hline $\begin{array}{l}\text { Patient cot } \\
\text { railings }\end{array}$ & NG & NG & NG & NG \\
\hline $\begin{array}{l}\text { Paticnt sidc } \\
\text { table }\end{array}$ & NG & NG & $\mathrm{NG}$ & NG \\
\hline $\begin{array}{l}\text { Crash trolley } \\
\text { phone }\end{array}$ & $\begin{array}{l}\text { NG } \\
\text { NG }\end{array}$ & $\begin{array}{l}\text { NG } \\
\text { NG }\end{array}$ & $\begin{array}{l}\text { NG } \\
\text { NG }\end{array}$ & NG \\
\hline
\end{tabular}

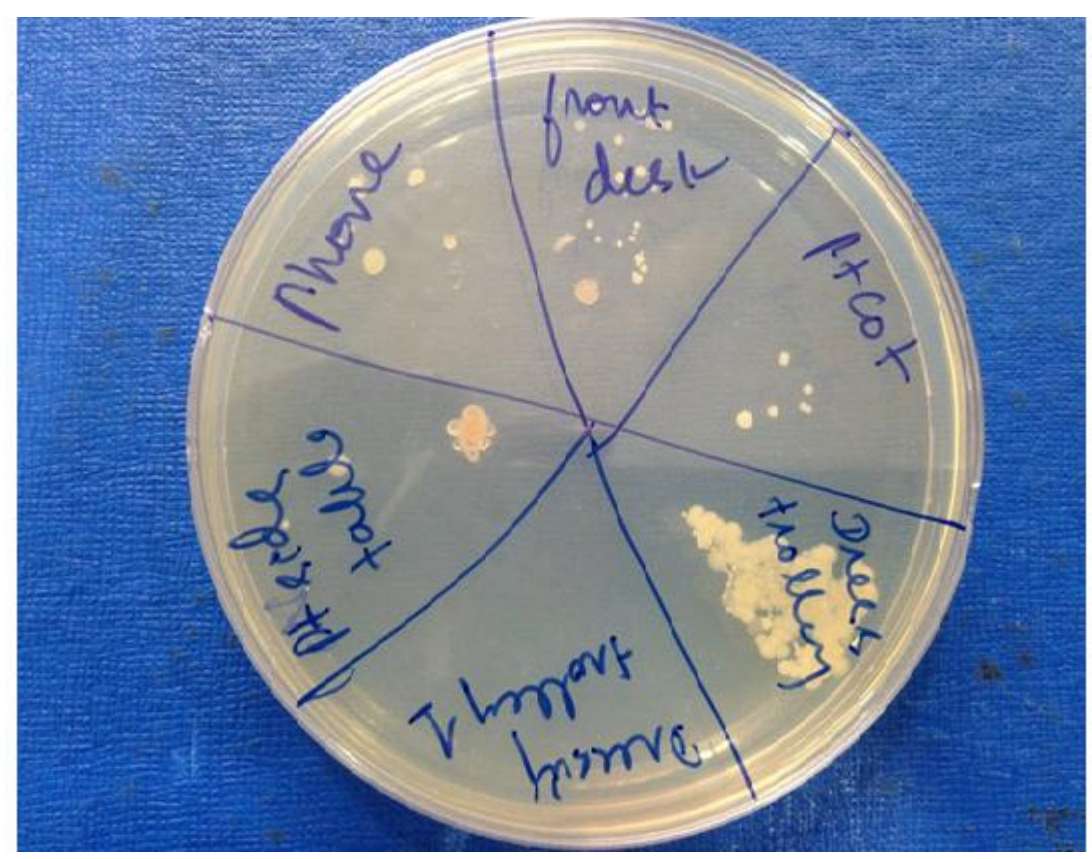




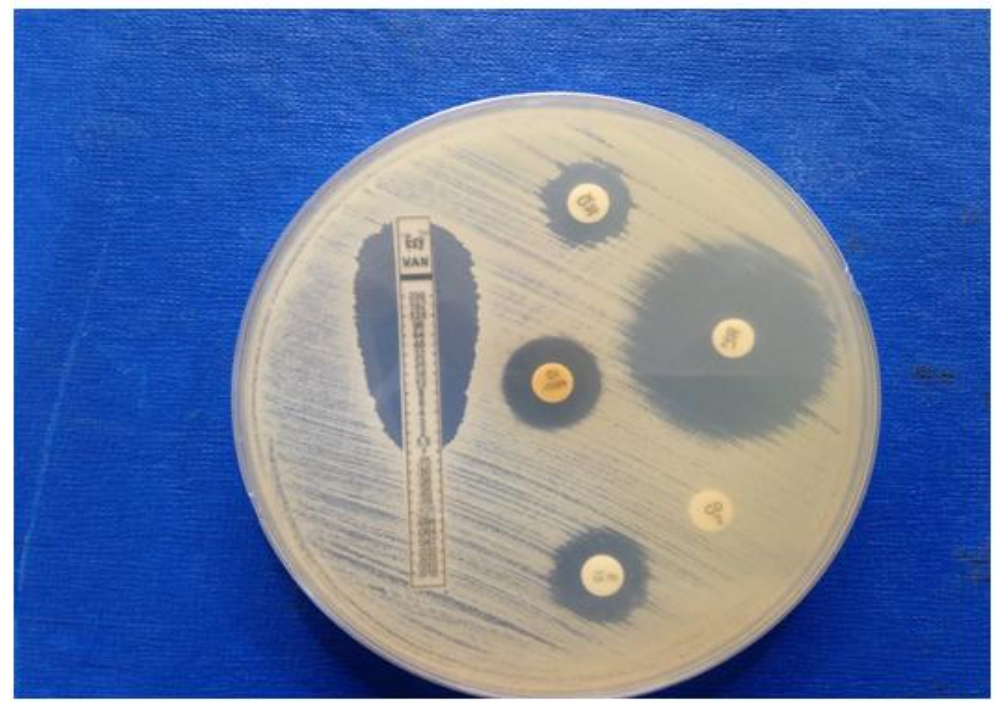

We used $1 \%$ hypochlorite for disinfection of surface which was economical and was also effective as it has bactericidal, sporicidal and virucidal action. We also tested the efficacy of the disinfectant after use by streaking on Nutrient agar plates and observing for growth, after aerobic incubation for $24 \mathrm{hrs}$ and set a protocol for using $1 \%$ hypochlorite for regular surface cleaning in our hospital, which is a new hospital (Table 2).

Understanding hand hygiene practices among HCWs is essential in planning intervention in health care. Risk factors for poor adherence to hand hygiene have been determined objectively in several observational studies or interventions to improve adherence (Dancer, 2014). Non adherence was higher in ICUs compared to internal medicine, during procedures that caused a high risk of bacterial contamination, when the intensity of the patient care was high. Lack of knowledge of guidelines for hand hygiene, lack of recognition of hand hygiene opportunities during patient care and lack of awareness of risk of cross contamination of pathogens are barriers for good hand hygiene practices. Regular cleaning of the places resulted in no growth of organisms. We used $1 \%$ hypochlorite for cleaning high risk areas like ICUs and OPD (minor OTs) and used 10\% hypochlorite for cleaning OTs. Standard precautions are designed to reduce the risk of transmission of microorganisms from both recognised and unrecognised sources of infection in the hospital. Pathogenic organisms from colonized and infected patients transiently contaminate the hands of staff during normal clinical activities and can then be transferred to other patients. Hand transmission is one of the most common methods of spread of infectious agents in health care facilities. Proper hand hygiene is an effective method of preventing the transfer of microbes between staff and patients. Increasing hand hygiene compliance by $1.5-2$ fold would result in a $25-50 \%$ decrease in the risk of health care associated infections (Boyce, 2016).

The importance of clean hospitals has not been widely accepted as a key component in infection control despite the increasing interest in HAI during the later part of $20^{\text {th }}$ century. This is to be welcomed since it is quite possible that accumulating data on environmental reservoirs and pathogen transmission in health care environments will also benefit people in their homes and the community at large (Goodman, 2008). Protocols should be adapted so that they lead to comparable conclusions. In conclusion, manual cleaning and disinfection of environmental surfaces in health care facilities, daily and during patient discharge are essential elements of infection prevention programme. Since there are many factors that make it 
difficult to achieve high rates of effective disinfection on a routine and sustained basis, continued efforts to improve the quality and consistency of traditional cleaning and disinfection practices are needed. Protocols should be adapted so that they lead to comparable conclusions about the efficacy of hand hygiene products. In our hospital we set a protocol to use $1 \%$ hypochlorite for surface disinfection and 10\% hypochlorite for OTs and it has been followed strictly.

\section{References}

Australian guidelines for the prevention and control of infection in health care. Common wealth council NHMRC 2010; 69-71.

Boyce. M.J. Modern technologies for improving cleaning and disinfection of environmental surfaces in hospitals. Anti Microbiol Infect.Control.2016; p 7-10.

Clinical and Laboratory Standards Institute (CLSI). Performance standards for Antimicrobial Susceptibility Testing; Twenty seventh Informational supplement. M100-S23. Wayne, PA: CLSI, 2017.

Dancer SJ. Controlling hospital acquired infection. Focus on the role of the environment and new technologies for decontamination. Clin.Microbiol.Rev. Oct 2014. 27(4): 665-90.

Ducel. G, Fabry. J, Nicolle. L. Prevention of hospital acquired infection. A practical guide Asian pacific society of infection control. 2002; 2nd edn., Pp. 17-19.

Goodman ER, Platt R, Bass R, Onderdon AB. Impact of environmental cleaning on environmental cleaning intervention in the presence of methicillin resistant staphylococcus aureus and vancomycin resistant enterococci on surface in intensive care unit rooms. Infect control hospepidemiol 2008; Jul29 (7): 593-9.

Ling $M$ L. The Asean guidelines for disinfection and sterilisation and sterilisation of instruments in health care facilities. 2008; Pp. 1-4.

Ling ML, Ching TY, Seto WH. A hand book of infection control for the Asian health care worker. $3^{\text {rd }}$ edn; 2011; Pp. 9-11.

Marfan FA, Grisenaurers S. Senkel. Impact of an intensive terminal cleaning and disinfection protocol involving selected hospital rooms on endemic health care associated infections rates of common pathogens at a tertiary care medical centre. Clin.Microbiol.Rev. Oct 2013; Pp. 666-80.

Moore G, and Griffith C. A laboratory evaluation of the decontamination properties of microfiber clothes. J.Hosp. Infect control. 2007; 569-73.

Nadova et al., Benefit of active approach to surveillance of hospital acquired infection, Epidemiology Sunnywale 2016; 6: 2.

Quinn, M.M., et al., Cleaning and disinfecting environmental surfaces in health care: toward an integrated framework for infection and occupational illness prevention. Am J. Infect. Control. 2015; (43): 424-34.

Ramphal L et al., Improving hospital staff compliance with environmental cleaning behaviour. Prov (BaylUniv.Med.Cent) 2014; 27(2): 88-91.

William et al., Requirements for infrastructure and essential activities of infection control and epidemiology in hospitals. A consensus panel report. Infect Control Epidemiol. 1998; 19: 114-24.

\section{How to cite this article:}

Subbalakshmi, E. 2018. Surveillance of Hospital Acquired Infection from Frequently Handled Surfaces in a Tertiary Care Teaching Hospital. Int.J.Curr.Microbiol.App.Sci. 7(02): 860-866. doi: https://doi.org/10.20546/ijcmas.2018.702.108 